\title{
Early effects of dexamethasone and anti-VEGF therapy in an inflammatory corneal neovascularization model
}

\author{
Pierfrancesco Mirabelli, Beatrice Bourghardt Peebo, Maria Xeroudaki, Marina Koulikovska \\ and Neil Lagali
}

\section{Linköping University Post Print}

\section{Tweet}

N.B.: When citing this work, cite the original article.

Original Publication:

Pierfrancesco Mirabelli, Beatrice Bourghardt Peebo, Maria Xeroudaki, Marina Koulikovska and Neil Lagali, Early effects of dexamethasone and anti-VEGF therapy in an inflammatory corneal neovascularization model, 2014, Experimental Eye Research, (125), 118-127.

http://dx.doi.org/10.1016/j.exer.2014.06.006

Copyright: Elsevier

http://www.elsevier.com/

Postprint available at: Linköping University Electronic Press

http://urn.kb.se/resolve?urn=urn:nbn:se:liu:diva-110279 


\section{HIGHLIGHTS}

We compared topical dexamethasone and anti-VEGF treatment in a model of rat corneal angiogenesis

Only dexamethasone inhibits early limbal capillary dilation and mature macrophage accumulation

Dexamethasone suppresses final corneal neovascularization by $>90 \%$ (anti-VEGFA by 14\%)

Both treatments delay early infiltration of CD11b+ cells, down-regulate VEGF-A, IL-6, FGF2 , TNF- $\alpha$, CCL2

In vivo longitudinal micro-morphologic assessment shows effects of treatments normally invisible 


\section{Early effects of dexamethasone and anti-VEGF therapy in an inflammatory corneal neovascularization model.}

Pierfrancesco Mirabelli ${ }^{*}$, Beatrice B Peebo ${ }^{*}$, Maria Xeroudaki, Marina Koulikovska, and Neil Lagali

Department of Ophthalmology, Institute for Clinical and Experimental Medicine, Faculty of Health Sciences, Linköping University, 58183 Linköping, Sweden

* Equal contribution

The authors wish to acknowledge financial contributions from Crown Princess Margareta's Foundation for the Visually Impaired, the County Council of Östergötland, and The Swedish Research Council.

Abstract word count: 375

Word count: 4836

None of the authors have any proprietary/financial interest to disclose.

Address for Correspondence:

Beatrice Peebo MD, PhD

Dept. of Ophthalmology

Institute for Clinical and Experimental Medicine

Faculty of Health Sciences

Linköping University

SE-581 83 Linköping

Sweden

Tel +4610 1033068

Fax +46101033065

Email beatrice.peebo@liu.se 


\section{ABSTRACT}

Inflammatory angiogenesis is the pathogenic mechanism of various sight-threatening eye diseases, among them corneal neovascularization. Current treatment options include steroids which have undesirable side effects, or anti-VEGF which has only limited efficacy. In an inflammatory environment, however, angiogenesis can be stimulated by numerous factors not directly targeted by anti-VEGF therapy. The aim of this study was to induce corneal inflammation leading to angiogenesis, and investigate the early, differential effects of steroid and anti-VEGF therapy at the cellular, tissue, and gene expression levels. Fifty-two Wistar rats received a single intrastromal corneal suture to induce a controlled inflammatory angiogenic response. Rats were subsequently treated with dexamethasone, rat specific antiVEGF, or goat IgG (control), topically 4 times daily for 7 days. In vivo confocal microscopy of the cornea was performed longitudinally from $5 \mathrm{~h}$ up to $7 \mathrm{~d}$ to investigate morphology at the cellular and tissue-level. In vivo photographic vessel analysis and immunohistochemistry were also performed. RT-PCR for VEGF-A, FGF-2, IL-6, TNF- $\alpha$, CXCL2, CCL2, CCL3 and DLL4 was performed at $24 \mathrm{~h}$, and for VEGF-A, IL-6, TNF- $\alpha$, FGF-2, CXCL2, CCL2, and CCL3 at 7 days. Early infiltration of CD11b+ myeloid cells into the cornea at $5 \mathrm{~h}$ post-suture was delayed by both treatments relative to controls; however neither treatment was able to suppress accumulation of myeloid cells at day 2 or 7 . Limbal vessel dilation was inhibited at 5 $\mathrm{h}$ by both treatments, but only dexamethasone showed sustained effect until day 2 . Early macrophage recruitment was also suppressed by dexamethasone (but not by anti-VEGF) until day 2. Dexamethasone furthermore suppressed corneal neovascularization at day 7 by over $90 \%$, whereas suppression by anti-VEGF was $14 \%$. Despite differential suppression of vessel dilation, macrophage recruitment, and vascular invasion, anti-VEGF and dexamethasone both down-regulated VEGF-A and IL-6 expression at $24 \mathrm{~h}$ with sustained effect to $7 \mathrm{~d}$. They also both down regulated FGF-2 and TNF- $\alpha$ at $24 \mathrm{~h}$ and CCL2 at $7 \mathrm{~d}$. In conclusion, antiangiogenic treatments influence early, pre-angiogenic tissue activity such as limbal vessel dilation, inflammatory cell infiltration of the stroma, and macrophage recruitment. Importantly, the differential effects of steroids and anti-VEGF treatment in suppressing neovascular growth could not be attributed to differential inhibition of several major angiogenic and inflammatory factors in the early pre-sprouting phase, including IL-6, VEGFA, FGF-2, TNF- $\alpha$, CCL2, CCL3, CXCL2, or DLL4.

\section{Key Words:}

Angiogenesis; neovascularization; cornea; inflammation; dexamethasone; anti-VEGF; confocal microscopy; rat. 


\section{Introduction}

Angiogenesis is a key mechanism in the pathogenesis of numerous diseases such as cancer, atherosclerosis, and eye diseases (Carmeliet, 2005). Inflammation can be a potent trigger of angiogenesis (Shaik-Dasthagirisaheb et al., 2013), especially in ocular conditions such as exudative macular degeneration, uveitis and infectious keratitis (Chang et al., 2001; Winterhalter et al., 2012). In the cornea, angiogenesis (or corneal neovascularization) has traditionally been treated with topical steroids in the active phase, whereas in a later phase only surgical procedures with often poor prognosis, if any therapy at all, are possible (Chang et al., 2001; Shakiba et al., 2009). Steroids are known from clinical practice to be effective, nevertheless they can also have frequent and serious side effects, including secondary glaucoma, corneal thinning and perforation, cataract, and herpes infection (Fel et al., 2012; Shakiba et al., 2009;). In recent years, anti-Vascular Endothelial Growth Factor treatment (anti-VEGF) has become first-line therapy in choroidal neovascularization (exudative maculopathy) (Kovach et al., 2012), and is also used to treat corneal neovascularization (offlabel) (Chang et al., 2012; Hosseini et al., 2012). While this more targeted treatment avoids the side-effects of steroids, experimental and clinical studies have shown only a limited reduction in corneal neovessels. Using locally-applied anti-VEGF by topical (Dastjerdi et al., 2009), subconjunctival (Petsoglou et al., 2013), intrastromal (Vieira et al., 2012), or intraocular (Avisar et al., 2010) route), neovessel reduction in the range of 15-20\% in experimental studies (Rocher et al., 2011), and of 36-61\% in clinical studies (Dastjerdi et al., 2009; König et al. 2009; Petsoglou et al. 2013) has been reported. Anti-VEGF may also have a shorter therapeutical window compared to steroids (Nakao et al., 2012). The reason for this limited and variable efficacy, however, remains unclear.

In the context of inflammation, damage to the corneal tissue can be inflicted before visible signs of vessel ingrowth. For example, stromal invasion of leukocytes (Bourghardt Peebo et al., 2007; Fagerholm and Gan, 2001; Gong and Koh, 2010; Nakao et al., 2012) which produce pro-angiogenic cytokines, precede and promote vessel invasion, and at a later stage could reactivate vessel growth upon cessation of treatment (Cursiefen et al., 2004; Gong and Koh, 2010; Lu et al., 2012; Sakurai et al., 2003; Sunderkötter et al., 1994; Tazzyman et al., 2013). Besides this paracrine function, evidence is mounting that inflammatory cells may have a more direct role in tissue remodeling and the formation of new vessels (Bourghardt Peebo et al., 2011; Fantin et al., 2010; Kim et al., 2009; Maruyama et al., 2005).

This early inflammation and damage is often invisible upon clinical examination. Current methods to assess the efficacy of anti-angiogenic treatments have overwhelmingly focused on examination with slit lamp and photography (Chen et al., 2009; Cheng et al., 2012; Chung and Lee, 2012; Dastjerdi et al., 2009; Yoeruek et al., 2008), partly due to the lack of specific methods to detect early inflammation and tissue damage in corneal neovascularization. We have previously showed that it is possible to detect early signs of inflammation by in vivo confocal microscopy (IVCM) (Peebo et al., 2010). A more complete assessment of antiangiogenic therapy would therefore include quantification of its suppressive effect on the dynamics of tissue inflammation at both the tissue and pathway level. Moreover, by investigating specific differences between anti-VEGF and steroid treatment, factors could be 
identified that may eventually combine the efficacy of dexamethasone with the higher specificity and lower side effects of anti-VEGF therapy.

The aim of this study was therefore to focus on the early phases of angiogenesis (presprouting and immediately post-sprouting) to investigate whether dexamethasone and antiVEGF treatments differentially influenced cells, tissue, vessels, and the gene expression of several major angiogenic and inflammatory pathways.

\section{Materials \& Methods}

\subsection{Suture-induced rat inflammatory corneal neovascularization assay:}

55 twelve- to sixteen-week-old male Wistar rats weighing 300 to $400 \mathrm{~g}$ (Scanbur AB, Sollentuna, Sweden) were used. All animals were treated following the Association for Research in Vision and Ophthalmology (ARVO) guidelines for the Use of Animals in Ophthalmic and Vision Research. With approval from the Linköping regional animal ethics review board, (application no. 7-13), rats were anesthetized using intraperitoneal injection of dexmeditomedine (Orion Pharma AB, Sollentuna, Sweden) and xylazine (Pfizer AB, Sollentuna, Sweden). After topical administration of $1 \%$ tetracaine (Chauvin Pharmaceuticals Ltd, London, England), a corneal stromal suture (10-0 nylon) was placed $1.5 \mathrm{~mm}$ from the temporal limbus as previously described (Bourghardt Peebo et al., 2011). The time of suture placement was considered to be $\mathrm{t}=0$. Left eyes were left untouched in sutured rats, and three rats were left un-sutured to provide negative control samples for Real Time Polymerase Chain Reaction (RT-PCR).

\subsection{Treatments}

After suturing the cornea, rats $(n=52)$ were randomly assigned to three groups where all animals received topical instillation of eye drops in the right eye four times daily for 7 days. Treatment groups were as follows: a) Anti-VEGF ( $n=18)$. A neutralizing rat specific goat polyclonal pan-VEGFA antibody (Cat. No AF 564, R\&D Systems, Minneaplois MN) was used, rather than the humanized monoclonal antibody bevacizumab, to enhance speciesspecific sensitivity. The antibody was diluted aseptically by PBS (PBS-A, APL, Kungens Kurva, Sweden) at a dose of $10 \mu \mathrm{g} / \mathrm{ml}$. b) Steroids $(\mathrm{n}=20)$ : The preservative-free dexamethasone $0.1 \%$ (Opnol, Clean Chemical Sweden AB, Borlänge, Sweden) was used. c) Control ( $\mathrm{n}=14)$ : Control rats received normal goat IgG antibody (Cat. No. 108-C, R\&D Systems), diluted aseptically by PBS at a dose of $10 \mu \mathrm{g} / \mathrm{ml}$. The untouched group $(\mathrm{n}=3)$ did not receive any treatment.

At either $24 \mathrm{~h}$, day 2, or day 7, animals were euthanized by intracardial injection of 100 $\mathrm{mg} / \mathrm{kg}$ pentobarbital sodium (Apoteket AB, Linköping, Sweden) while under deep anaesthesia. The entire cornea without scleral rim was then excised and the temporal portion was prepared and immediately frozen to $-70^{\circ} \mathrm{C}$ for immunohistochemistry or to $-20^{\circ} \mathrm{C}$ for RTPCR. Six corneas from three untouched rats were used for RT-PCR as negative controls. 


\subsection{In vivo confocal microscopy}

In this study we used laser scanning in vivo confocal microscopy (IVCM), with an instrument clinically approved for use in imaging the eye (Heidelberg Retinal Tomograph 3 with Rostock Corneal Module, Heidelberg Engineering). The microscope was equipped with a 63x/0.95 NA water-immersion objective (Zeiss, Oberkochen, Germany), that provides an en face view of a $400 \mu \mathrm{m}$ x $400 \mu \mathrm{m}$ corneal area at a selectable corneal depth. The IVCM imaging technique has been described in detail elsewhere (Bourghardt Peebo et al., 2011; Peebo et al.,

2011,2010). The focal depth of the HRT3 was initially adjusted to image the corneal epithelial surface, and the lateral and transverse microscope alignments were adjusted to locate the suture in the real-time image display window. Once the suture was located, the focal plane was adjusted axially to locate inflammatory cells, limbal blood vessels, or stromally-located angiogenic vessels. Typically, these structures of interest were confined to a thin subepithelial stromal region from $0-40 \mu \mathrm{m}$ below the basal epithelium. Digital images were recorded at 5 frames/s while lateral, transverse, and axial controls were adjusted during image capture to locate and follow the path of cells or vessels from the limbus to the suture area. IVCM has been shown to be a valuable tool for imaging of various cells in transparent tissue, noninvasively, in a time-lapse manner, without the need for cell labeling (Bourghardt Peebo et al., 2011; Peebo et al., 2011,2010).

Five animals from each treatment group were randomly chosen for in vivo follow up with IVCM. At 5h, days 2 and 7, animals were anesthetized, eyes were photographed in the operating microscope, and IVCM was performed. Once the suture was located, the microscope field of view $(400 \mu \mathrm{m} \times 400 \mu \mathrm{m})$ was translated temporally to locate the limbal region. A typical examination consisted of 10 image sequences with each sequence containing 100 successive digital image frames.

Inflammatory cell migration from limbus into the corneal stroma was analyzed from selected representative images. Image measurements were then performed using Image J (ImageJ software, developed by Wayne Rasband, National Institutes of Health, Bethesda, MD; available at http://rsb.info.nih.gov/ij/index.html). To enhance assay reproducibility, images with clear inflammatory cell infiltration from the same corneal depth (depth where limbal vessels were in focus) were chosen. All images were coded to mask the observer to the treatment group of a given eye. For evaluation of cell migration at $5 \mathrm{~h}$, the distance between the limbal arcade and the most distal leading inflammatory cells in the corneal stroma was measured with Neuron J linear alignment tool (Meijering et al., 2004). This distance value was used in statistical analysis.

To quantify inflammatory cell infiltration at days 2 and 7, three distinct coded IVCM images per sutured cornea were first selected from the stromal region between the limbus and suture (no limbus or suture visible). Next, each image was pre-processed in ImageJ by applying the following built-in ImageJ functions: background subtraction, sharpening, noise reduction, thresholding to exclude the brightest $5 \%$ of pixels, conversion to binary, and the watershed function to separate adjoined cells. After pre-processing, cells in the binary images were 
automatically counted using the built-in 'analyze particles' function in ImageJ. All separate regions larger than 36 square pixels were deemed as inflammatory cells and were included in the automatic cell count. The automatic count was performed twice (to include and exclude cells on image borders), and the two counts were averaged. Cell counts per frame were then used in the statistical analysis.

Limbal vessel expansion in response to the different treatments was quantified on IVCM images of the limbal arcade at $5 \mathrm{~h}$ and day 2. Images with distinct vessels with blood flow were selected, and were in-focus and generally at the same corneal depth. Blood vessels had a constant diameter and were measured once per vessel or twice in a loop (once in each connecting vessel) using ImageJ.

Mature macrophages were first identified by immunofluorescent staining. They had a characteristic in vivo morphologic appearance (Peebo et al., 2011) and preferentially accumulated at the suture site. IVCM images of the suture site at days 2 and 7 were then selected from the treated corneas, based on the criteria of the presence of at least one mature macrophage in the image. Up to 3 images depicting distinct areas with mature macrophages were chosen from each cornea. Macrophages were then manually counted using the 'Cell Counter' plugin to ImageJ, and counts were recorded for statistical analysis.

\subsection{In vivo photographic vessel analysis}

Photographs from the operating microscope from 25 sutured rats at day 7 were used to measure total vessel length and vessel invasion area. Using ImageJ software, color photographs were first digitally converted to red free images, then inverted and sharpened. NeuronJ was then used to trace the path of visible blood vessels in a semi-automated manner (Figure 1). Total vessel length was defined as the total length (in $\mathrm{mm}$ ) of all traced vessels in a given cornea, while vessel invasion area was defined by the area of the polygon with verticies given by the furthest invading vessel tips in the cornea and by the limbal border. The ImageJ line and area calculator tools were used for quantification. Vessels were traced and invasion area was measured by two independent observers, and the average value of the two observers was taken.

\subsection{Immunohistochemistry}

Frozen corneas were thawed and rinsed in PBS; fixed in acetone; rinsed in PBS 3 times; blocked in $10 \%$ normal donkey serum (Jackson ImmunoResearch Europe, Newmarket, UK) and incubated with primary antibodies overnight. The next day, samples were rinsed, blocked, and incubated with secondary antibodies overnight. For double immunostaining, this procedure was repeated. The primary antibodies used were: pan-endothelial marker CD31/PECAM-1 (Santa Cruz Biotechnology Inc. Santa Cruz, CA, USA), myeloid lineage marker CD11b (Santa Cruz), and a marker for mature rat macrophages KiM2R (Abcam PLC, Cambridge, UK). Secondary antibodies (Jackson) included Dylight 549 and Dylight 488. All imaging was performed using a laser-scanning confocal fluorescence microscope (Nikon Eclipse E600 or Zeiss LSM 700) equipped with 40x/1.30 NA oil-immersion or 20x/0.75 NA objective lenses. Samples were scanned under single or dual laser excitation and a digital 
camera was used to record images. In all cases, control samples were used and omission of the primary antibody eliminated cell-specific staining.

\subsection{Real-time quantitative RT-PCR}

42 corneas were harvested for reverse transcriptase polymerase chain reaction (RT-PCR) analysis: 6 corneas from 3 untouched rats as negative control samples, and 12 corneas from each treatment group. 9 corneas per treatment group were excised $24 \mathrm{~h}$ after placing the suture, and 3 per treatment group were excised at day 7 .

Total RNA from each corneal sample was isolated with RNeasy Mini Kit (Qiagen). RNA concentrations were determined using a Nanodrop ND-2000 spectrophotometer (Nanodrop Technologies), and the complementary DNA (cDNA) was synthesized from the total RNA (100 ng) using a SuperScript ${ }^{\circledR}$ VILO ${ }^{\text {TM }}$ cDNA Synthesis Kit (Invitrogen) in accordance with the manufacturer's instructions. PCR reactions were performed on all corneal samples (nonpooled) using TaqMan Fast Advanced Master Mix and TaqMan Gene Expression Assays (Applied Biosystems) in a total volume of $20 \mu \mathrm{l}$. Real-time PCR conditions were $50 \mathrm{oC}$ for 2 $\min , 95^{\circ} \mathrm{C}$ for $1 \mathrm{~min}$ and then 40 cycles of $95^{\circ} \mathrm{C}$ for $15 \mathrm{~s}, 60^{\circ} \mathrm{C}$ for $20 \mathrm{~s}$. The primers used for PCR analysis were as follows: rat IL-6 (Applied Biosystems, Cat. No. Rn01410330_m1), VEGFa (Cat. No. Rn01511601_m1), Tumor Necrosis Factor alfa (TNF- $\alpha$, Cat. No. Rn01525859_g1), Chemokine C - C motif ligand 2 (CCL2, Cat. No. Rn00580555_m1), Chemokine C - C motif ligand 3 (CCL3, Cat.No Rn01464736_g1), Chemokine (C-X-C motif) ligand (CXCL2, Cat.No Rn00586403), Delta like ligand 4 (DLL4, Cat.No Rn01512886_m1), Fibroblast Growth Factor (FGF-2, Cat.No Rn00570809). The Ct values for samples were determined, and relative target gene mRNA expression was calculated by the $\mathrm{Ct}$ method, using $\beta$-actin (Cat. No. Rn00667869_m1) and Glyceraldehyde Phosphate Dehydrogenase (GAPDH, Cat. No. Rn01775763_g1) as endogenous housekeeping control genes. Gene expression level was reported relative to the average relative expression level in the negative control samples. All reactions were carried out using an ABI PRISM 7900HT Real-Time PCR system (Applied Biosystems) and were repeated in triplicate.

\subsection{Statistical analysis}

Statistical comparison of blood vessel lumen diameter, total vessel length, vessel invasion area, inflammatory cell migration at $5 \mathrm{~h}$, inflammatory cell presence at day 2 and 7 , macrophage presence at day 2 and 7, and gene expression across groups was performed using one-way analysis of variance (ANOVA). Normality in the distribution of data was determined by the Kolmogorov-Smirnov test. Where data was normally-distributed, the one-way ANOVA was used with multiple pairwise comparisons performed by the Student-NewmanKeuls method. For non-normally distributed data, the Kruskal-Wallis one-way ANOVA on ranks was used, with pairwise multiple comparisons performed using Dunn's Method. All comparisons were performed using statistical software (SigmaStat, Syastat Software Inc. Chicago, IL, USA) and a two-tailed value of $p<0.05$ was considered statistically significant. 


\section{Results}

\subsection{Early migration of myeloid cells is delayed by anti-VEGFA and dexamethasone treatment.}

Early migrating inflammatory cells were observed to enter the cornea en masse (Bourghardt Peebo et al., 2011; Li et al., 2006) with a clear wavefront between invaded and un-invaded corneal stroma (Figure 2A). Treatment with dexamethasone and anti-VEGF significantly slowed the migration of these $\mathrm{CD} 11 \mathrm{~b}+$ myeloid cells at $5 \mathrm{~h}$ in comparison to controls $(\mathrm{P}=$ 0.03; Figure $2 \mathrm{~B}, \mathrm{C}$ ), but no difference was noted between anti-VEGF and dexamethasone treatment.

By day 2, the corneal stroma from the limbus to the suture site was densely infiltrated by myeloid cells in all groups. Cell quantification revealed a diminished number of myeloid cells in the anti-VEGF group in comparison to the dexamethasone group $(\mathrm{P}=0.03)$, but more stromal edema was present in anti-VEGF treated corneas, compared to the dexamethasone group, (Figure 3A) making visualization of inflammatory cells more difficult . This difference did not persist to day 7, where myeloid cell counts did not differ between treatment groups ( $\mathrm{P}$ $=0.34$ ), although the number of cells at day 7 was slightly reduced in all groups compared to day 2. (Figure 3).

\subsection{Sustained suppression of early limbal vessel dilation by dexamethasone.}

In vivo measurement of vessel dilation revealed that early-phase limbal vessel dilation at $5 \mathrm{~h}$ was inhibited in both treatment groups in comparison to controls $(\mathrm{P}<0.001$; Figure 4A). By day 2, dexamethasone-treated corneas continued to significantly inhibit dilation relative to controls $(\mathrm{P}<0.001)$ while anti-VEGF treatment did not $(\mathrm{P}>0.05$; Figure 4). Measurements of limbal vessel diameter at day 7 could not be performed since corneas in anti-VEGF treated and control groups were vascularized and hence, original limbal vessels were no longer identifiable in vivo.

\subsection{Early macrophage recruitment is suppressed by dexamethasone.}

The in vivo morphology of macrophages is known from an earlier study (Peebo et al., 2011) and was in addition confirmed by ex vivo whole mount immunostaining with the mature macrophage marker Ki-M2R (Figure 5). Mature macrophages were observed in vivo to accumulate at the suture site. Macrophage quantification at the suture site revealed that dexamethasone treatment significantly reduced the recruitment of macrophages at day 2 in comparison to anti-VEGF treatment and controls $(\mathrm{P}=0.027)$. By day 7 , the number of macrophages had increased in all groups, but the total number of macrophages in anti-VEGF and dexamethasone-treated corneas was still significantly reduced in comparison to controls $(\mathrm{P}=0.001$; Figure 5). Macrophages in the dexamethasone-treated group were reduced relative to the anti-VEGF group at day 7 , but this difference did not reach statistical significance $(\mathrm{P}=$ $0.33)$. 


\subsection{Effect of topical dexamethasone and anti-VEGF treatment on corneal neovascularization}

Photographic analysis in vivo revealed that dexamethasone treatment significantly suppressed corneal neovascularization at day 7 (Figure 6). In comparison to controls, total vessel length was reduced by $95.3 \%$ and vessel invasion area by $93.1 \%(\mathrm{P}<0.001$ for both measures, relative to both anti-VEGF and controls). The inhibitory effect of anti-VEGF was significantly weaker than dexamethasone $(\mathrm{P}<0.05)$ with a reduction of vessel length by $14.4 \%$ and invasion area by $13.8 \%$ relative to controls at day 7 ( $P>0.05$ for both measures; Figure 6).

\subsection{Modulation of inflammatory and angiogenic gene expression by treatment}

To assess the effect of treatments on the gene expression of several key inflammatory and angiogenic mediators, but also to verify efficacy of topical drug delivery, RT-PCR was performed at day 7 for VEGFA, FGF-2, IL-6, CXCL2, CCL2, CCL3 and TNF- $\alpha$, in the same corneas examined longitudinally by IVCM. The factors chosen represent major and well known angiogenic, inflammatory, and macrophage-related factors. In sutured corneas, expression of all cytokines was significantly up-regulated relative to non-sutured negative control corneas ( $\mathrm{P}<0.001$; Figure $7 \mathrm{~B}$ ), except for FGF2 which was slightly down-regulated $(\mathrm{P}>0.05)$. In both dexamethasone and anti-VEGF groups, the expression of VEGFA, IL-6 and CCL2 was significantly down-regulated $(\mathrm{P}<0.05)$ compared to control IgG treatment. There was no significant difference, however, between dexamethasone and anti-VEGF groups in gene expression for these three factors ( $\mathrm{P}>0.05)$. Expression of TNF- $\alpha$, CXCL2, and CCL3 did not differ between groups.

Due our observation of a large difference in corneal neovascularization between treatments despite similar gene expression at day 7 , we decided to investigate gene expression earlier in the pre-sprouting, inflammatory phase. Delta-like ligand 4 (DLL4) was additionally included, due to its regulation of early sprouting of neovessels (Suchting et al., 2007). RT-PCR was therefore performed using corneal tissue samples extracted at $24 \mathrm{~h}$ for VEGF-A, FGF-2, IL-6, TNF- $\alpha$, CXCL2, CCL2, CCL3, and DLL4 (Figure 7A). VEGF-A, FGF-2, IL-6, and TNF- $\alpha$ were all significantly down-regulated in both treatment groups relative to controls, with no significant difference between anti-VEGF and dexamethasone groups for these genes. Expression of CXCL2, CCL2, CCL3, and DLL4 did not differ between the groups at 24h.

In summary, VEGFA and IL-6 were strongly down-regulated by both dexamethasone and anti-VEGF in the early pre-sprouting phase (at $24 \mathrm{~h}$ ), and this inhibition continued to day 7. Even FGF-2 and TNF- $\alpha$ were down-regulated at $24 \mathrm{~h}$ by both treatments. No significant down-regulation of CCL2 expression could be detected at $24 \mathrm{~h}$, but this down-regulation became evident by day 7. No modification of the expression of CCL 3 and CXCL2 could be detected at either $24 \mathrm{~h}$ or at day 7.

\section{Discussion}


In this study, in vivo longitudinal examination of the same corneas revealed that antiangiogenic treatments can influence early, pre-angiogenic tissue activity such as limbal vessel dilation, inflammatory cell infiltration of the stroma, and macrophage accumulation. Importantly, this early activity was perturbed by both dexamethasone and anti-VEGF treatment within the first two days after suturing, before the first angiogenic sprouts typically appear at the limbus in our model (Bourghardt Peebo et al., 2011).

Clearly both anti-VEGF and dexamethasone suppress numerous cytokines, results that also confirmed drug penetration in our topical treatment model. Generally, the penetration of topically instilled dexamethasone into the cornea is known from clinical experience and earlier experimental studies (Bessonova et al., 2011; Hoffart et al., 2010; Hos et al., 2011). Topical anti-VEGF antibodies have similarly shown good penetration into the cornea, particularly after local disruption of the epithelial barrier and induction of inflammation and angiogenesis (Rocher et al., 2011; Stevenson et al., 2012; Yoeruek et al., 2008). In the present study, RT-PCR also revealed a significant effect on many cytokines belonging to inflammatory and angiogenic pathways as early as $24 \mathrm{~h}$, indicating the rapid effect of the topical treatments.

Differences in vessel dilation and inflammatory cell migration between treatment groups were visible as early as $5 \mathrm{~h}$ after suturing. While both dexamethasone and anti-VEGF treatment delayed cell migration and vessel dilation at this early phase, these effects had subsided in the anti-VEGF group by day 2. At day 2, in dexamethasone-treated corneas, limbal vessels continued to resist dilation, and accumulation of mature macrophages at the suture site was suppressed despite an increased number of infiltrating myeloid cells (macrophages likely collect at the suture in an attempt to digest foreign material (van Putten et al., 2013), but even play a role in producing VEGF and other cytokines (Lu et al., 2008). Interestingly, these two parameters in the pre-sprouting phase at day 2 appeared to correlate with final neovascular invasion at day 7 , while the early migration of inflammatory myeloid cells and total myeloid cell presence did not appear to relate to the final development of neovessels. The inhibitory effect of steroids and anti-VEGF treatment on early cell invasion is in accordance with earlier reports demonstrating delayed migration of inflammatory cells in an ex vivo setting (Hos et al., 2011;Nakao et al., 2012, 2007; Oh et al., 2009). Little is known, however, about the effect of anti-angiogenic treatments on the dynamics of microvascular dilation, a process which is an important step in the early angiogenic process. Steroids have been shown to have an inhibitory effect on vessel caliber in a chorioallantoic membrane model (McKay et al., 2008) and in a clinical study in patients with diabetic macular edema (Wickremasinghe et al., 2008), indicating an inhibitory effect of steroids on inflammatory cytokines inducing vessel expansion. The ability of anti-VEGF treatment to reduce mature vessel caliber has been demonstrated after topical instillation of bevacizumab in clinical studies (Cheng et al., 2012; König et al., 2009; Stevenson et al., 2012), an effect likely arising from blocking the permeability properties of VEGF.

One surprising finding revealed by the in vivo analysis was the dense infiltration of inflammatory myeloid cells in dexamethasone-treated corneas that persisted from day 2 through 7. Despite the absence of blood vessels in these corneas, inflammatory cells were 
abundant. A similar infiltration of neutrophils into the cornea following steroid treatment has been shown in earlier studies in corneal tissue (Nakao et al., 2012, 2007), while another study implicated glucocorticoids in the recruitment of specific anti-inflammatory leukocyte subsets (Kim et al., 2009). Moreover, in the resolution phase of inflammation, glucocorticoids have been shown to facilitate apoptosis of eosinophils, but undesirably prolong neutrophil survival (Cox 1995). Technical artifacts such as better visualization of inflammatory cells in corneas with less stromal edema (dexamethasone group), or the limitations of a two-dimensional analysis of inflammatory cells present at various depth layers in the cornea may have impacted the results. Further investigation of the inflammatory cells, their associated cytokines, and their pro- or anti-angiogenic role in the current model is warranted.

Anti-VEGF treatment did not appear to suppress myeloid cell recruitment at day 2 and 7 in our model in contrast to other rat models of corneal injury, where inflammatory cells were significantly suppressed by subconjunctival administration of bevacizumab (Oh et al., 2009; Sener et al., 2011) but not ranibizumab (Sener et al., 2011). Conflicting results may be due to different models, species-dependent effects (we used rat-specific anti-VEGF), quantification techniques, and drug delivery methods. The longitudinal in vivo analysis, however, could shed light on dynamic changes in inflammation whereas fixed tissue specimens only provide the status of inflammation at a specific time point.

In the present study, dexamethasone suppressed corneal neovascularization by over $90 \%$. Suppression of corneal neovasularization by $57-75 \%$ with dexamethasone has been reported previously in rodent models (Hoffart et al., 2010; Hos et al., 2011; Nakao et al., 2012, 2007). Anti-VEGFA treatments, however, have had a comparatively poorer efficacy in both animal and clinical studies (Bahar et al., 2008; Hoffart et al., 2010; Farid and Zaki, 2010), with some studies noting only borderline reduction in neovascular area (Oh et al., 2009) while others report greater reduction in invasion area relative to controls (Bock et al., 2007; DratvimanStorobinsjy et al., 2009; Manzano et al., 2007). In this study, a reduction of $14 \%$ in invasion area relative to sham-treated controls did not reach significance. This result may indicate limited effectiveness of the anti-VEGF treatment (Dastjerdi et al., 2009), but may also partly reflect the small vascularized area of the rat cornea in our temporal suture model. The model, designed for longitudinal in vivo examination, induces vessels in a well-defined region of the cornea between the limbus and the suture, limited to about one-tenth of the cornea's total surface area. In other animal models with several central sutures (Bock et al. 2007; Cursiefen et al., 2004; Hos et al., 2011) or a large-area alkali burn (Dratviman-Storobinsky et al., 2009; Gong and Koh, 2010; Hoffart et al., 2010; Sener et al., 2011) a large region of the cornea can become vascularized, which allows for greater sensitivity in detecting significant reductions in invasion area, but a less predictable and controlled pattern of vascularization.

Our in vivo findings led us to investigate whether the topical anti-angiogenic treatments, while in general not successful in inhibiting myeloid cell recruitment to the cornea, may effectively block their pro-angiogenic cytokine release (Gong and Koh, 2010; Sunderkötter et al., 1994; Tazzyman et al., 2013). Interestingly, Zakaria et al. (2012) have shown from studies of human tears that inflammatory cytokines such as IL-6, IL-8 are positively correlated with the presence of corneal neovascularization. Inhibition of early recruitment or maturation of 
macrophages by anti-angiogenic agents may also play an important role in later corneal neovascularization (Cursiefen et al., 2004; Lu et al., 2012; Sakurai et al., 2003; Sunderkötter et al., 1994). As expected, VEGF-A expression was suppressed in the treatment groups, alongside with IL-6, a widespread inflammatory cytokine that has been shown to have bidirectional associations with VEGF-A (Tartour et al., 2011; Zakaria et al 2012). This effect was already detected in the early phase $(24 \mathrm{~h})$ and persisted until day 7 . Several studies in different models of corneal inflammation have found a significantly reduced expression of IL6 after treatment with bevacizumab (Chung and Kang, 2010; Oh et al., 2009), demonstrating the close relation between VEGF and IL-6 in inflammation. A further interesting finding in this study was the ability of anti-VEGF treatment to down-regulate FGF-2 at $24 \mathrm{~h}$, to an equal degree as dexamethasone, given that the FGF family is considered to represent aVEGFindependent pathway. This suppression did, however not persist to day 7. Another potent inflammatory cytokine, TNF- $\alpha$, was significantly down-regulated by both treatments in the early phase, but this effect was not detectable at day 7. CCL2, also called monocyte chemotactic protein-1 (MCP-1) has been shown to promote recruitment of monocytes, memory T-cells, and dendritic cells to the inflammation site (Goede et al. 1999; Ueno et al., 2000). Its expression did not appear to be modified by treatment at $24 \mathrm{~h}$, but its downregulation at day 7 in treated corneas paralleled the reduced presence of mature macrophages at the same time point. Despite this reduction in macrophage recruitment, however, neovascularization was still abundant in the anti-VEGF group, indicating a complexity of macrophage activity and the possible contribution of unidentified pro-angiogenic factors derived from macrophages or other cell types within the inflammatory infiltrate.

Although the effect of anti-VEGF treatment was not restricted to VEGF-A, dexamethasone is likely to influence many other inflammatory and angiogenic genes that anti-VEGF does not target, or may even upregulate. For instance, significant up-regulation of Insulin-like Growth Factor 1 (IGF-1) and MIP-2 (CXCL2) after bevacizumab treatment has been reported in a corneal alkali burn model (Dratviman-Storobinsky et al., 2009), while tumor studies have demonstrated the potential of anti-VEGF treatment to induce alternative FGF-2-driven angiogenesis (Alessi et al., 2009). The difference in neovascularization observed in our model could not be explained by CXCL2 or FGF-2, providing the motivation to examine larger sets of genes, for example using microarray-based techniques, and the detailed composition of the cellular infiltrate.

In summary, we have shown that dexamethasone inhibits both early limbal capillary dilation and early macrophage recruitment in a corneal neovascularization model. These early inhibitory effects, not observed with anti-VEGFA treatment, paralleled the inhibition of corneal neovascular sprouting. Preliminary gene expression analysis indicates that dexamethasone likely acts through the suppression of factors peripheral to several major proinflammatory and proangiogenic pathways.

The authors wish to thank Catharina Traneus-Röckert for immunostaining of the corneal samples, and Per Fagerholm for critical review of the manuscript.

\section{References}


Alessi P., Leali D., Camozzi M., Cantelmo A., Albini A., Presta M., 2009. Anti-FGF2 approaches as a strategy to compensate resistance to anti-VEGF therapy: long-pentraxin 3 as a novel antiangiogenic FGF2-antagonist. Eur. Cytokine Netw. 20, 225-234. doi: 10.1684/ecn.2009.0175

Avisar I., Weinberger D., Kremer I., 2010. Effect of subconjunctival and intraocular bevacizumab injections on corneal neovascularization in a corneal model. Curr. Eye Res. 35, 108-115. doi: 10.3109/02713680903429007.

Bahar I., Kaiserman I., McAllum P., Rootman D., Slomovic A., 2008. Subconjunctival bevacizumab injection for corneal neovascularization. Cornea 27, 142-147. doi: 10.1097/ICO.0b013e318159019f.

Bessonova J., Meyer-Lindenberg A., Bäumer W., Kietzmann M, 2011. Tissue distribution of dexamethasone in feline ocular structures following single topical application of dexamethasone as an ointment or suspension. Vet. Ophthalmol. 14, 109-113. doi: 10.1111/j.1463-5224.2010.00851.x.

Bock F., Onderka J., Dietrich T., Bachmann B., Kruse F.E., Paschke M., Zahn G., Cursiefen C., 2007. Bevacizumab as a potent inhibitor of inflammatory corneal angiogenesis and lymphangiogenesis. Invest. Ophthlamol. Vis. Sci. 48, 2545-2552.

Bourghardt Peebo B., Fagerholm P., Traneus-Röckert C., Lagali N., 2011. Time-lapse in vivo imaging of corneal angiogenesis: the role of inflammatory cells in capillary sprouting. Invest. Ophthalmol. Vis. Sci. 52, 3060-3068. doi: 10.1167/iovs.10-6101.

Bourghardt Peebo B., Gan L., Sun X-F., Knutsen A., Rearden A., Fagerholm P., 2007. Expression of the focal adhesion protein $\mathrm{PINCH}$ in normal and alkali-injured corneas and the role of PMNs. Acta Ophthalmol. Scand. 85, 395-400.

Carmeliet P., 2005. Angiogenesis in life, disease and medicine. Nature 438, 932-936.

Chang J.H., Garg N., Lunde E., Han K.Y., Jain S., Azar D.T., 2012. Corneal neovascularization: an anti-VEGF therapy review. Surv. Ophthalmol. 57, 415-429.

Chang J.H., Gabison E.E., Kato T., Azar D.T., 2001. Corneal neovascularization. Curr. Opin. Ophthalmol. 12, 242-249.

Chen W.L., Lin C.T., Lin N.T., Tu I.H., Li J.W., Chow L.P., Liu K.R., Hu F.R., 2009.

Subconjunctival injection of bevacizumab (Avastin) on corneal neovascularization in different rabbit models of corneal angiogenesis. Invest. Ophthalmol. Vis. Sci. 50, 1659-1665. doi:

10.1167/iovs.08-1997.

Cheng S.F., Dastjerdi M.H., Ferrari G., Okanobo A., Bower K.S., Ryan D.S., Amparo F., Stevenson W., Hamrah P., Nallasamy N., Dana R., 2012. Short-term topical bevacizumab in the treatment of stable corneal neovascularization. Am. J. Ophthalmol. 154, 940-948. doi: 10.1016/j.ajo.2012.06.007.

Chung S.K., Lee M.Y., 2012. Treatment of corneal neovascularization by topical application of ascorbic acid in the rabbit model. Cornea 31, 1165-1169. doi:

10.1097/ICO.0b013e318241433b. 
Chung S.K , Kang S., 2010. The effect of subconjuctival combined treatment of bevacizumab and triamcinolone acetonide on corneal neovascularization in rabbits. Cornea 29, 192-196. doi: 10.1097/ICO.0b013e3181b1c82f.

Cox G., 1995. Glucocorticoid treatment inhibits apoptosis in human neutrophils. Separation of survival and activation outcomes. J. Immunol. 154, 4719-4725.

Cursiefen C., Chen L., Borges L., Jackson D., Cao J., Radziejewski C., D'Amore P.A., Dana M.R., Wiegand S.J., Streilein J.W., 2004. VEGF-A stimulates lymphangiogenesis and hemangiogenesis in inflammatory neovascularization via macrophage recruitment. J. Clin. Invest. 113, 1040-1050.

Dastjerdi M.H., Al-Arfaj KM, Nallasamy N., Jurkunas U.V., Pineda R. 2nd, Pavan-Langston D, Dana R., 2009. Topical bevacizumab in the treatment of corneal neovascularization: results of a prospective, open-label, noncomparative study. Arch Ophthalmol. 127, 381-389. doi: 10.1001/archophthalmol.2009.18.

Dratviman-Storobinsky O., Lubin B.C., Hasanreisoglu M., Goldenberg-Cohen N., 2009. Effect of subconjuctival and intraocular bevacizumab injection on angiogenic gene expression levels in a mouse model of corneal neovascularization. Mol. Vis. 15, 2326-2338.

Ehrchen J., Steinmüller L., Barczyk K., Tenbrock K., Nacken W., Eisenacher M., Nordhues U., Sorg C., Sunderkötter C., Roth J., 2007. Glucocorticoids induce differentiation of a specifically activated, anti-inflammatory subtype of human monocytes. Blood 109, 1265 1274.

Fagerholm P., Gan L., 2001. Leukocytes in the early events of corneal neovascularization. Cornea 20, 96-99.

Fantin A., Vieira J.M., Gestri G., Denti L., Schwarz Q., Prykhozhij S., Peri F., Wilson S.W., Ruhrberg C, 2010. Tissue macrophages act as cellular chaperones for vascular anastomosis downstream of VEGF-mediated endothelial tip cell induction. Blood 116, 829-840. doi: 10.1182/blood-2009-12-257832.

Farid S.F., Zaki A.A., 2010. Subconjunctival bevacizumab for corneal neovascularization. Acta Ophthalmol. 88, 868-871. doi: 10.1111/j.1755-3768.2009.01585.x.

Fel A., Aslangul E., Le Jeunne C., 2012. Eye and corticosteroid's use. Presse Med. 41, 414421.

Goede V., Brogelli L., Ziche M., Augustin H.G., 1999. Induction of inflammatory angiogenesis by monocyte chemoattractant protein-1. Int. J. Cancer 82, 765-770.

Gong Y., Koh D.R., 2010. Neutrophils promote inflammatory angiogenesis via release of preformed VEGF in an in vivo corneal model. Cell Tissue Res. 339, 437-448. doi: 10.1007/s00441-009-0908-5.

Hoffart L., Matonti F., Conrath J., Daniel L., Ridings B., Masson G., Chavane F., 2010. Inhibition of corneal neovascularization after alkali burn: comparison of different doses of bevacizumab in monotherapy or associated with dexamethasone. Clin. Exp. Ophthalmol.38, 346-352. 
Hos D., Saban D.R., Bock F., Regenfuss B., Onderka J Masli S, Cursiefen C., 2011. Suppression of inflammatory corneal lymphagniogenesis by application of topical corticosteroids. Arch Ophthalmol. 129, 445-452. doi: 10.1001/archophthalmol.2011.42

Hosseini H., Nowroozzadeh M.H., Salouti R, Nejabat M, 2012. Anti-VEGF therapy with bevacizumab for anterior segment eye disease. Cornea 31, 322-334.

Kim S.J., Kim J.S., Papadopoulos J., Wook Kim S., Maya M., Zhang F., He J., Fan D., Langley R., Fidler I.J., 2009. Circulating monocytes expressing CD31: implications for acute and chronic angiogenesis. Am. J. Pathol. 174, 1972-1980. doi:10.2353/ajpath.2009.080819.

Kovach J.L., Schwartz S.G., Flynn H.W. Jr, Scott I.U., 2012. Anti-VEGF Treatment Strategies for Wet AMD. J. Ophthalmol. 786870. doi: 10.1155/2012/786870.

König Y., Bock F., Horn F., Kruse F., Straub K., Cursiefen C., 2009. Short and long term safety profile and efficacy of topical bevacizumab (Avastin) eye drops against corneal neovascularization. Graefes Arch Clin. Exp. Ophthalmol. 247, 1375-1382. doi: 10.1007/s00417-009-1099-1.

Li Z., Burns A.R., Smith W., 2006. Two waves of neutrophil emigration in response to corneal epithelial abrasion: distinct adhesion molecule requirements. Invest. Ophthalmol. Vis. Sci. 47, 1947-1955.

Lu P., Li L., Liu G., Baba T., Ishida Y., Nosaka M., Kondo T., Zhang X., Mukaida N, 2012. Critical role of TNF- $\alpha$-induced macrophage VEGF and iNOS production in the experimental corneal neovascularization. Invest. Ophthalmol. Vis. Sci. 53, 3516-3526. doi:

10.1167/iovs.10-5548

Lu P., Li L., Wu Y., Mukaida N., Zhang X., 2008. Essential contribution of CCL3 to alkaliinduced corneal neovascularization by regulating vascular endothelial growth factor production by macrophages. Mol. Vision 200814, 1614-1622.

Manzano R.P., Peyman G.A., Khan P., Carvounis P.E., Kivilcim M., Ren M., Lake J.C., Chévez-Barrios P., 2007. Inhibition of experimental corneal neovascularisation by bevacizumab (Avastin). Br. J. Ophthalmol. 91, 804-807.

Maruyama K., Ii M., Cursiefen C., Jackson D.G., Keino H., Tomita M., Van Rooijen N., Takenaka H., D'Amore P.A., Stein-Streilein J., Losordo D.W., Streilein J.W., 2005. Inflammation-induced lymphangiogenesis in the cornea arises from CD11b-positive macrophages. J. Clin. Invest. 115, 2363-2372.

McKay T.I., Gedeon D.J., Vickerman M.B., Hylton A.G., Ribita D., Olar H.H., Kaiser P.K., Parsons-Wingerter P., 2008. Selective inhibition of angiogenesis in small blood vessels and decrease in vessel diameter throughout the vascular tree by triamcinolone acetonide. Invest. Ophthalmol. Vis. Sci. 49, 1184-1190. doi: 10.1167/iovs.07-1329.

Meijering E., Jacob M., Sarria J.C.F., Steiner P., Hirling H., Unser M., 2004. Design and Validation of a Tool for Neurite Tracing and Analysis in Fluorescence Microscopy Images. Cytometry Part A 58, 167-176. Url: http://www.imagescience.org/meijering/software/neuronj/ 
Nakao S., Zandi S., Lara-Castillo N., Taher M., Ishibashi T., Hafezi-Moghadam A., 2012.

Larger therapeutic window for steroid versus VEGF-A inhibitor in inflammatory angiogenesis: surprisingly similar impact on leukocyte infiltration. Invest. Ophthalmol. Vis. Sci. 53, 3296-3302. doi: 10.1167/iovs.11-8114.

Nakao S., Hata Y., Miura M., Noda K., Kimura Y.N., Kawahara S., Kita T., Hisatomi T., Nakazawa T., Jin Y., Dana M.R., Kuwano M., Ono M., Ishibashi T., Hafezi-Moghadam A., 2007. Dexamethasone inhibits interleukin-1beta-induced corneal neovascularization: role of nuclear factor-kappaB-activated stromal cells in inflammatory angiogenesis. Am. J. Pathol. 171, 1058-1065.

Oh J.Y., Kim M.K., Shin M.S., Lee H.J., Lee J.H., Wee W.R., 2009. The anti-inflammatory effect of subconjunctival bevacizumab on chemically burned rat corneas. Curr. Eye. Res. 34, 85-91. doi: 10.1080/02713680802607740.

Peebo BB., Fagerholm P., Traneus-Röckert C., Lagali N., 2011. Cellular level characterization of capillary regression in inflammatory angiogenesis using an in vivo corneal model. Angiogenesis 14, 393-405. doi: 10.1007/s10456-011-9223-3.

Peebo BB., Fagerholm P., Traneus-Röckert C., Lagali N., 2010. Cellular-level characterization of lymph vessels in live, un-labeled corneas by in vivo confocal microscopy. Invest. Ophthalmol. Vis. Sci. 51, 830-835. doi: 10.1167/iovs.09-4407.

Petsoglou C., Balaggan K.S., Dart J.K.G., Bunce C., Xing W., Ali R.R., Tuft S.J., 2013. Subconjunctival bevacizumab induces regression of corneal neovascularisation: a pilot randomized placebo-controlled double-masked trial. Br. J. Ophthalmol. 97, 28-32. doi: 10.1136/bjophthalmol-2012-302137.

Rocher N., Behar-Cohen F., Pournaras J.A., Naud M.C., Jeanny J.C., Jonet L., Bourges J.L., 2011. Effects of rat anti-VEGF antibody in a rat model of corneal graft rejection by topical and subconjunctival route. Mol. Vis. 17, 104-112.

Sakurai E., Anand A, Ambati B.K., van Rooijen N., Ambati J., 2003. Macrophage depletion inhibits experimental choroidal neovascularization. Invest. Ophthalmol. Vis. Sci. 44, 35783585 .

Sener E., Yuksel N., Yildiz D.K., Yilmaz B., Ozdemir O., Caglar Y., Degirmenci E., 2011. The impact of subconjuctivally injected EGF and VEGF inhibitors on experimental corneal neovascularization in rat model. Curr. Eye. Res. 36, 1005-1013.

Shaik-Dasthagirisaheb Y.B., Varvara G., Murmura G., Saggini A., Potalivo G., Caraffa A., Antinolfi P., Tete' S., Tripodi D., Conti F., Cianchetti E., Toniato E., Rosati M., Conti P., Speranza L., Pantalone A., Saggini R., Theoharides T.C., Pandolfi F., 2013. Vascular endothelial growth factor (VEGF), mast cells and inflammation. Int. J. Immunopathol Pharmacol. 26, 327-335.

Shakiba Y., Mansouri K., Arshadi D., Rezaei N., 2009. Corneal neovascularization: molecular events and therapeutic options. Recent Pat. Inflamm. Allergy Drug Discov. 3, 221-231.

Stevenson W., Cheng S.F., Dastjerdi M., Ferrari G., Dana R., 2012. Corneal

Neovascularization and the utility of topical VEGF inhibition: ranibizumab (Lucentis) vs bevacizumab (Avastin). Ocul. Surf. 10, 67-83. doi: 10.1016/j.jtos.2012.01.005. 
Suchting S., Freitas C., le Noble F., Benedito R., Bréant C., Duarte A., Eichmann A., 2007. The Notch ligand Delta-like 4 negatively regulates endothelial tip cell formation and vessel branching. Proc. Natl. Acad. Sci. U. S. A. 104, 3225-30.

Sunderkötter C., Steinbrink K., Goebeler M., Bhardwaj R., Sorg C., 1994. Macrophages and angiogenesis. J. Leukocyte Biol. 55, 410-422.

Tartour E., Pere H., Maillere B., Terme M., Merillon N., Taieb J., Sandoval F., QuintinColonna F., Lacerda K., Karadimou A., Badoual C., Fridman W.H., Oudard S., 2011. Angiogenesis and immunity: a bidirectional link potentially relevant for the monitoring of antiangiogenic therapy and the development of novel therapeutic combination with immunotherapy. Cancer Metastasis Rev. 30, 83-95. doi: 10.1007/s10555-011-9281-4.

Tazzyman S., Niaz H., Murdoch C., 2013. Neutrophil-mediated tumour angiogenesis: Subversion of immune responses to promote tumour growth. Semin. Cancer Biol. 23, 149158. doi: 10.1016/j.semcancer.2013.02.003.

Ueno T., Toi M., Saji H., Muta M., Bando H., Kuroi K., Koike M., Inadera H., Matsushima K., 2000. Significance of macrophage chemoattractant protein-1 in macrophage recruitment, angiogenesis, and survival in human breast cancer. Clin. Cancer Res. 6, 3282-3289.

van Putten S.M., Ploeger D.T., Popa E.R., Bank R.A., 2013. Macrophage phenotypes in the collagen-induced foreign body reaction in rats. Acta Biomater. 9, 6502-6510. doi:

10.1016/j.actbio.2013.01.022.

Vieira A.C., Höfling-Lima A.L., Gomes J.A., Freitas Dd., Farah M.E., Belfort Jr. R., 2012. Intrastromal injection of bevacizumab in patients with corneal neovascularization. Arq. Bras. Oftalmol. 75, 277-279.

Wickremasinghe S.S., Rogers S.L., Gillies M.C., Zhu M., Wong T.Y., 2008. Retinal vascular caliber changes after intravitreal triamcinolone treatment for diabetic macular edema. Invest Ophthalmol. Vis. Sci. 49, 4707-4711. doi: 10.1167/iovs.08-1678.

Winterhalter S., Joussen A.M., Pleyer U., Stübiger N., 2012. Inflammatory choroidal neovascularization. Klin. Monbl. Augenheilkd. 229, 897-904.

Yoeruek E., Ziemssen F., Henke-Fahle S., Tatar O., Tura A., Grisanti S., Bartz-Schmidt K.U., Szurman P., Tübingen Bevacizumab Study Group, 2008. Safety, penetration and efficacy of topically applied bevacizumab: evaluation of eyedrops in corneal neovascularization after chemical burn. Acta Ophthalmol. 86, 322-328.

Zakaria N, Van Grasdorff S, Wouters K, Rozema J, Koppen C, Lion E, Cools N, Berneman Z, Tassignon MJ, 2012. Human tears reveal insights into corneal neovascularization. PLoS One. 7(5):e36451. 
Figure Captions

Figure 1. Method for vessel tracing. (A) Color photographs were digitally processed to an inverted red free image. (B) For maximal clarity, images were inverted and sharpened. (C) Neuron $\mathbf{J}$ was used by two independent observers to trace all visible blood vessels in a semiautomated manner.

Figure 2. Early migration of myeloid cells. (A) Early inflammatory cell migration observed by in vivo confocal microscopy was delayed in dexamethasone- and anti-VEGF-treated animals in comparison to controls. Cells reached the suture site in controls, but were delayed in dexamethasone- and anti-VEGF-treated corneas. All images are $400 \times 400 \mu \mathrm{m}$. (B) The myeloid origin of cells was confirmed by CD11b expression (red) while limbal vessels expressed CD31(green). Image taken at 20× magnification. (C) Migration distance of inflammatory cells at $5 \mathrm{~h}$ (suture at $1500 \mu \mathrm{m}$ ). Error bars indicate SD. Treatment with dexamethasone and anti-VEGF significantly delayed migration of myeloid cells in comparison to controls $(\mathrm{P}<0.05)$.

Figure 3. Late accumulation of myeloid cells. (A) By day 2, IVCM imaging revealed all corneas to be densely infiltrated by myeloid cells. At day 7, infiltration of inflammatory cells persisted. All images are $400 \times 400 \mu \mathrm{m}$. (B) Cell quantification at day 2 revealed a reduced number of myeloid cells in anti-VEGF relative to dexamethasone-treated corneas $(\mathrm{P}=0.03)$ but no difference in comparison to control. This disparity did not persist to day 7 , where no difference in myeloid cell infiltration between groups was noted.

Figure 4. Early limbal vessel dilation. (A) Limbal vessel dilation at 5h was inhibited in both treatment groups (anti-VEGF and dexamethasone) in comparison to controls ( $\mathrm{P}<0.001$, single asterisk). At day 2, dexamethasone-treated corneas continued to exhibit significantly reduced limbal vessel diameter relative to controls ( $\mathrm{P}<0.001$, double asterisk), in contrast to anti-VEGF treatment, where limbal vessel dilation was no longer suppressed $(\mathrm{P}>0.05)$. (B) Representative IVCM images depicting suppressed limbal vessel dilation in dexamethasonetreated corneas. All images are $400 \times 400 \mu \mathrm{m}$.

Figure 5. Recruitment of mature macrophages. (A) Mature macrophages (white arrows) observed with IVCM in the suture area at day 2 and day 7 are more numerous in the control group in comparison to treatment groups. Mature macrophages are confirmed by positivity for the Ki-M2R marker (green). All in vivo images are $400 \times 400 \mu \mathrm{m}$; fluorescence image taken at 20× magnification. (B) Macrophage quantification at the suture site at day 2 revealed that 
dexamethasone significantly suppressed recruitment of macrophages in comparison to antiVEGF and controls $(\mathrm{P}=0.027)$. At day 7 , the number of macrophages increased in all groups, but remained suppressed in anti-VEGF and dexamethasone groups relative to controls $(\mathrm{P}=$ $0.001)$.

Figure 6. Quantification of corneal neovascularization. (A) At day 2, photographic observation confirmed limbal vessel dilation (white arrows) in anti-VEGF and control groups, but not in dexamethasone-treated corneas. By day 7, almost no vessels were visible in dexamethasone-treated corneas, except for a few thin vessels close to limbus (black arrow). Slight edema (black asterisk) was evident in the suture area. Corneas in anti-VEGF and control groups were densely vascularized to the suture (suture is located $1.5 \mathrm{~mm}$ from the limbal arcade). (B) Quantification of neovascularization at day 7 revealed that dexamethsone significantly inhibited total vessel length by $95.3 \%$ and vessel invasion area by $93.1 \%$ compared to controls $(\mathrm{P}<0.001)$. The inhibitory effect of anti-VEGF was significantly weaker than dexamethasone $(\mathrm{P}<0.05)$ with a reduction of vessel length by $14.4 \%(\mathrm{P}>0.05)$ and invasion area by $13.8 \%(\mathrm{P}>0.05)$ in compared to controls.

Figure 7. Expression of inflammatory and angiogenic genes by RT-PCR. (A) Gene expression for VEGFA, FGF-2, IL-6, TNF- $\alpha$, CXCL2, DLL4, CCL2, CCL3 at $24 \mathrm{~h}$ in all groups. VEGFA, FGF-2, IL-6, and TNF- $\alpha$ were all significantly suppressed in both treatment groups, with no significant difference between anti-VEGF and dexamethasone. The expression of CXCL2, CCL2, CCL3, and DLL4 were not influenced by treatments. All results represent 3-5 corneas per treatment group. (B) Gene expression at day 7 for VEGFA, FGF-2, IL-6, TNF- $\alpha$, CXCL2, CCL2, and CCL3 in all groups. In sutured corneas, all cytokines were significantly up-regulated in comparison the native non-sutured cornea $(\mathrm{P}<0.001)$, except for FGF2 which was slightly down-regulated $(\mathrm{P}>0.05)$. Dexamethasone and anti-VEGF down-regulated the expression of VEGFA, IL-6 and CCL2 (P < 0.05) relative to IgG controls. There was no difference in gene expression between dexamethasone and anti-VEGF treatment groups for any of the cytokines $(\mathrm{P}>0.05)$. TNF- $\alpha$ was down-regulated in both dexamethasone and antiVEGF treated groups relative to IgG controls, but not to a significant level. All results represent 3 corneas per treatment group, except for FGF-2 and CXCL2, where the IgG group consisted of 2 corneas. 
Click here to download high resolution image
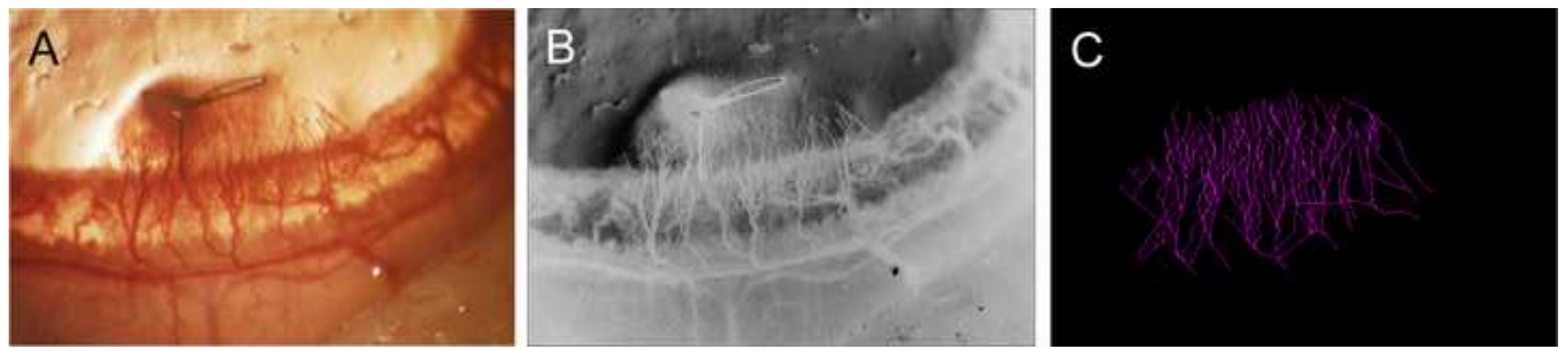
Click here to download high resolution image

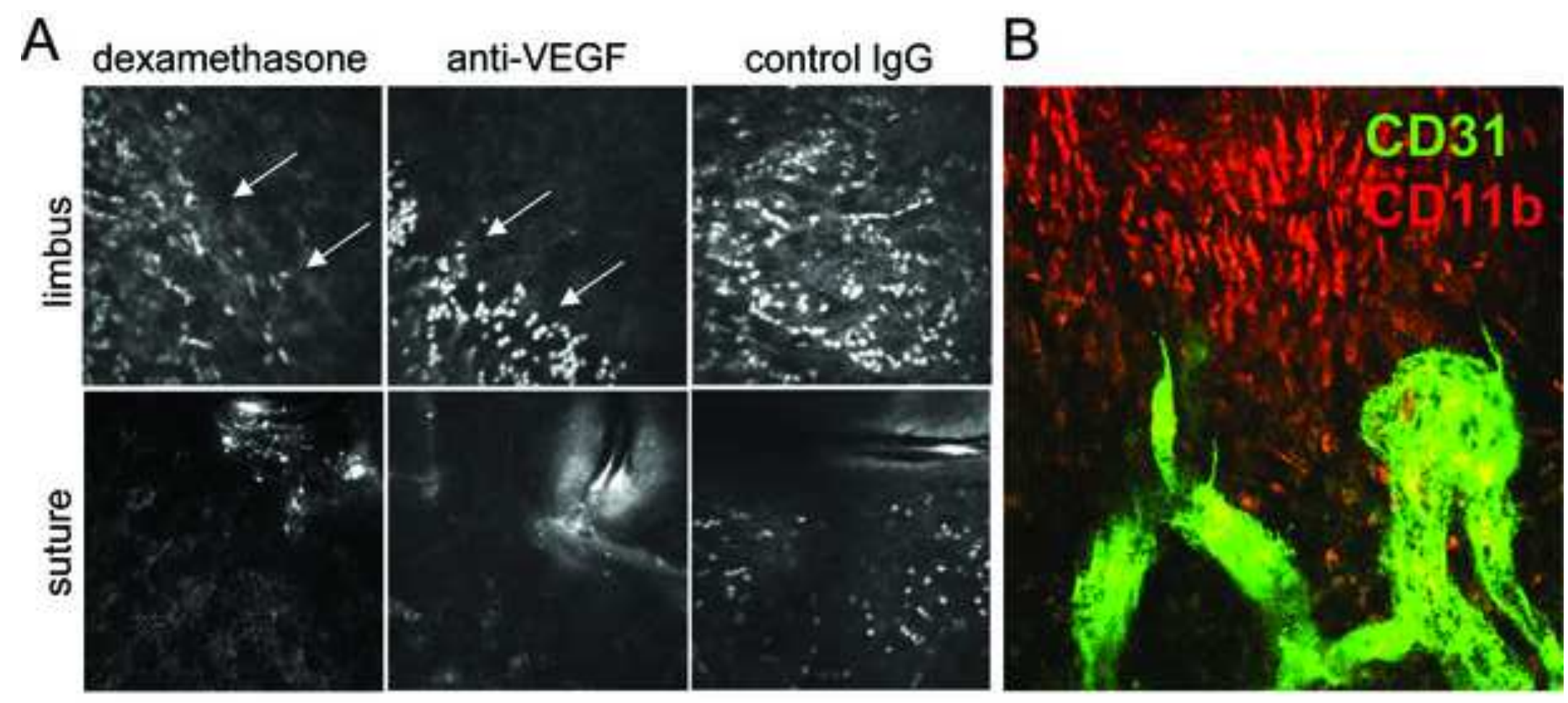

C

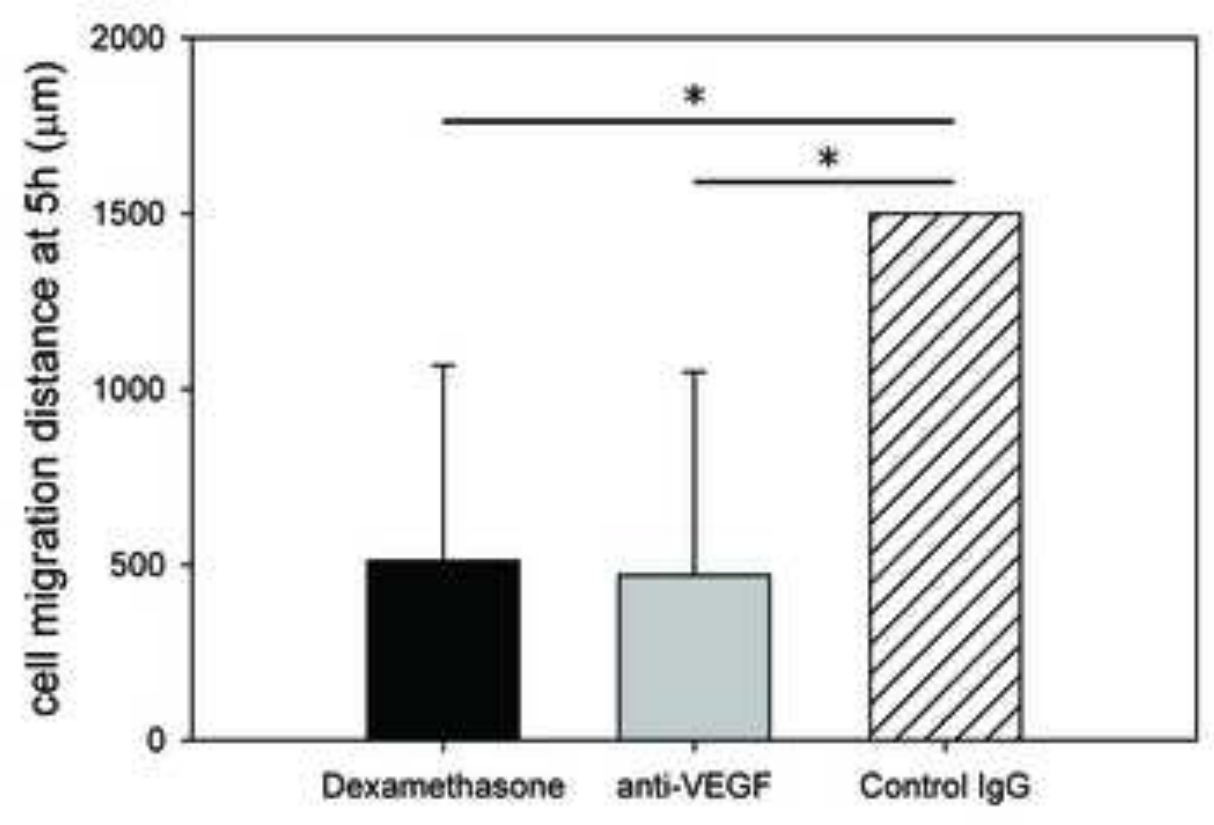


Click here to download high resolution image
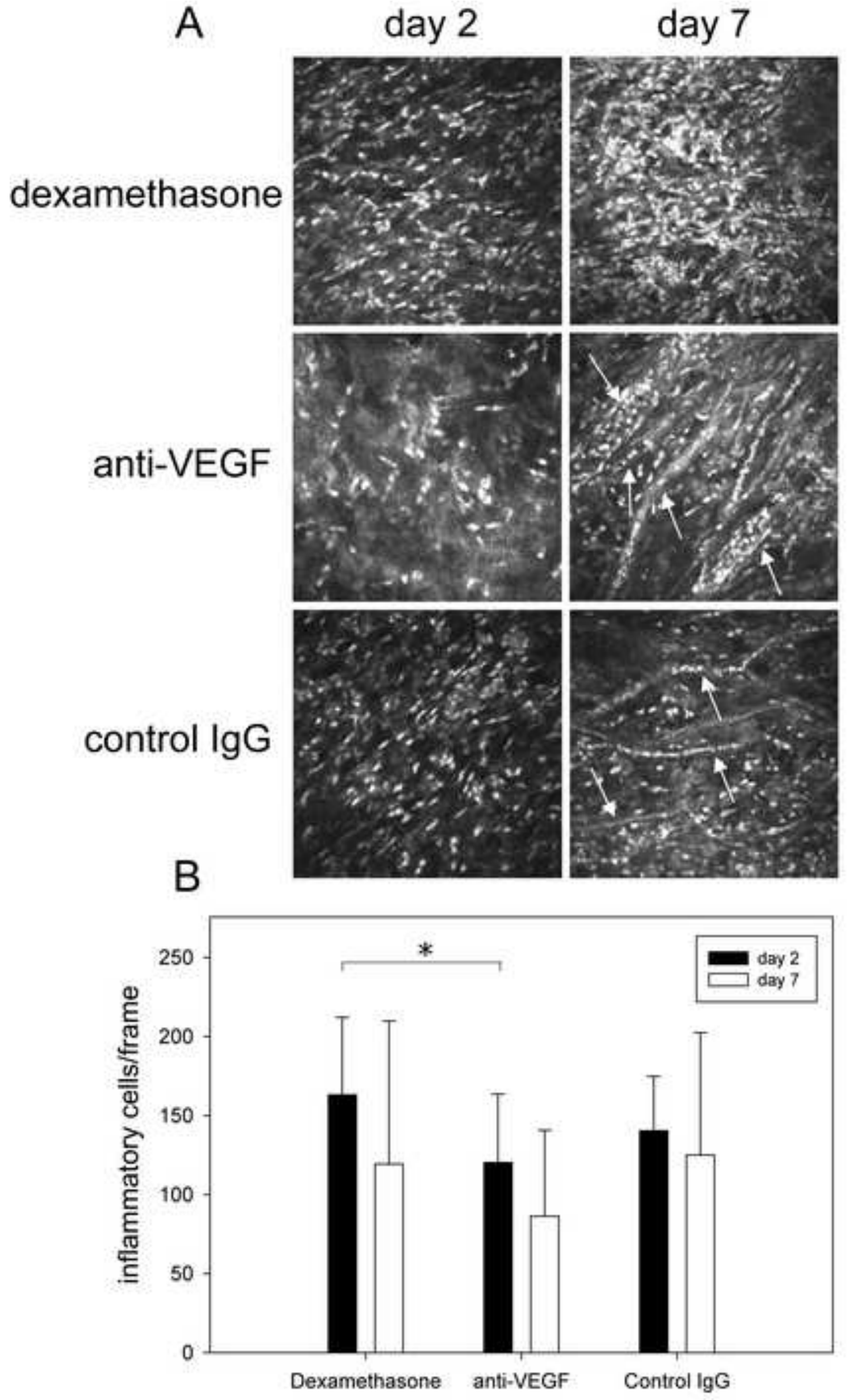
Figure 4 revised

Click here to download high resolution image

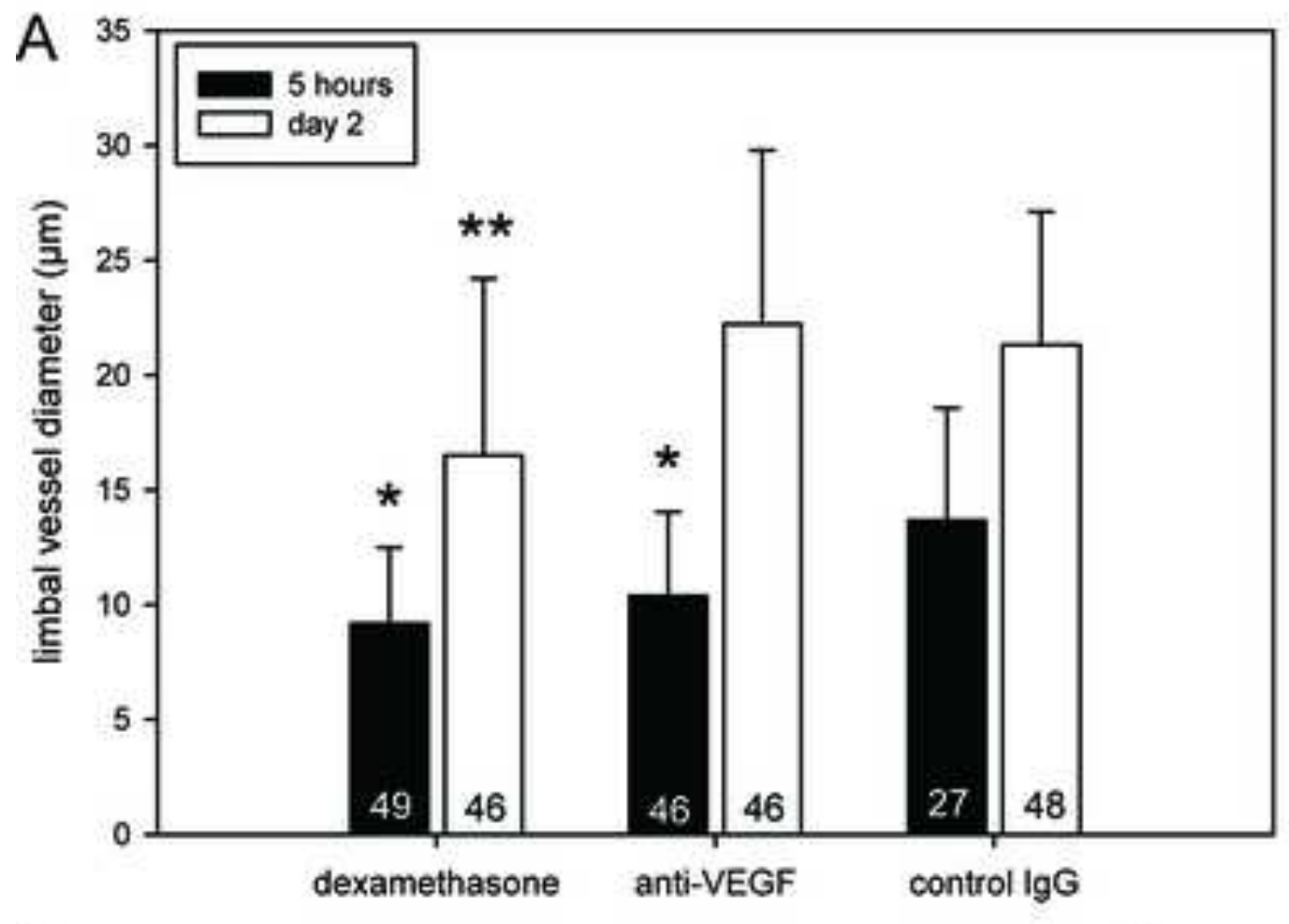

B

dexamethasone

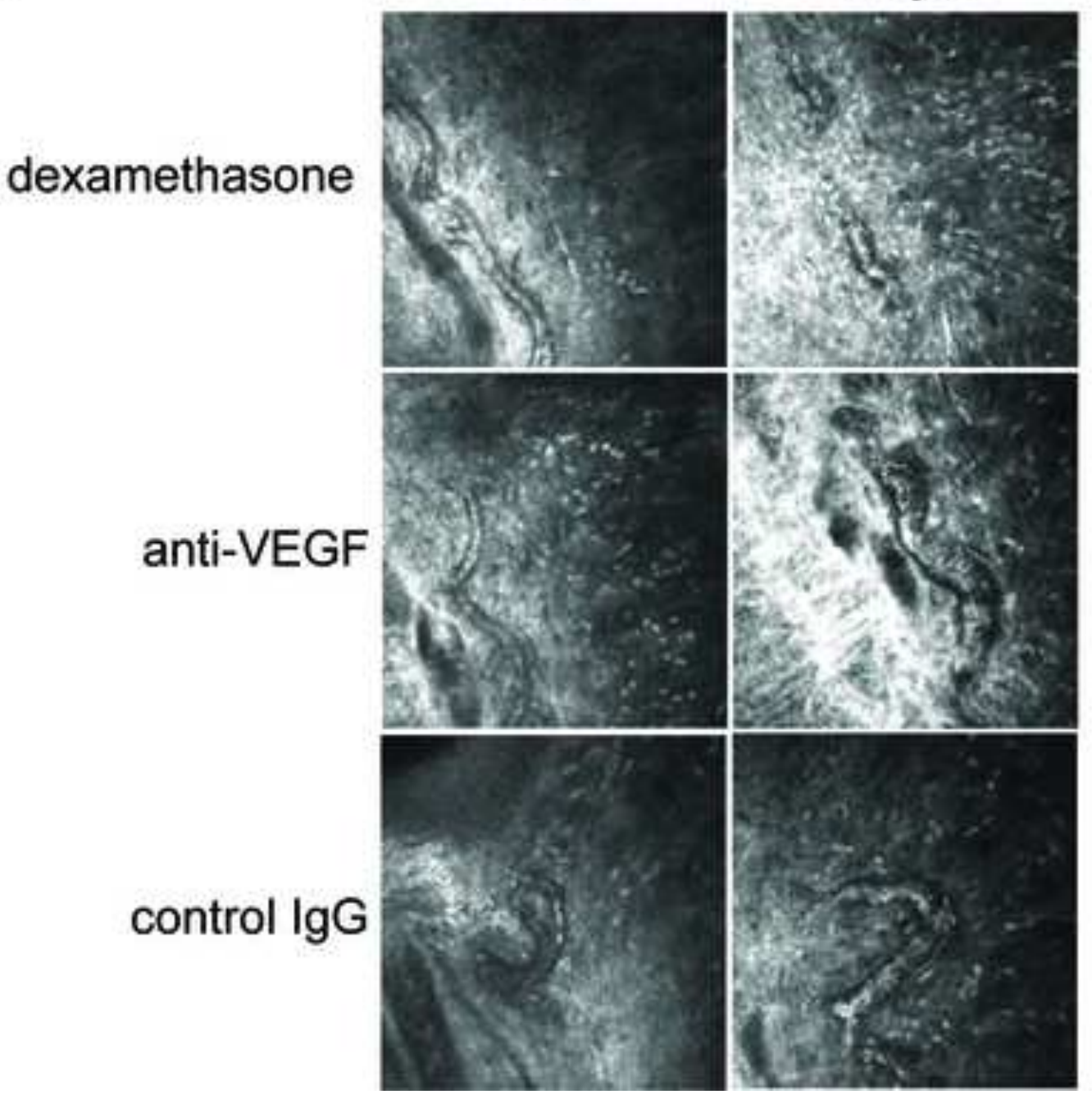

$5 \mathrm{~h}$

day 2 


\section{A dexamethasone}
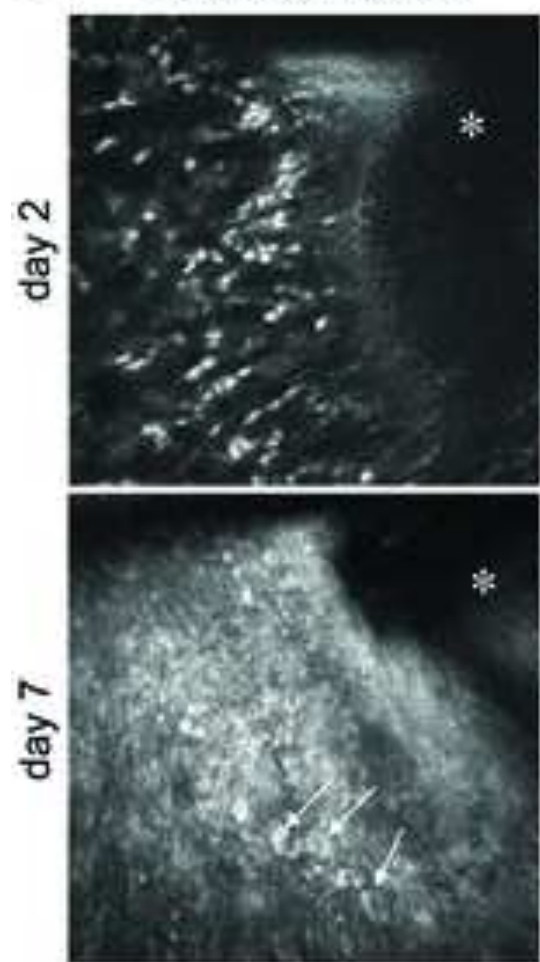

$*$
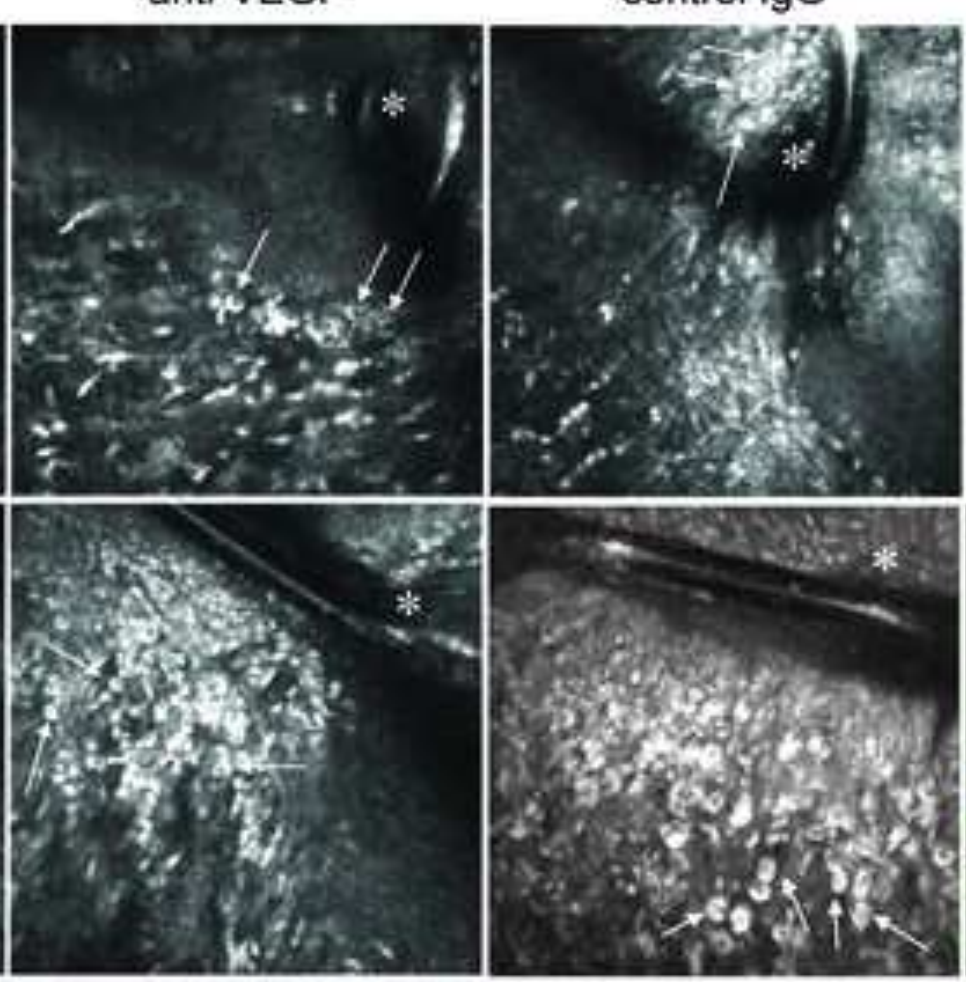

B

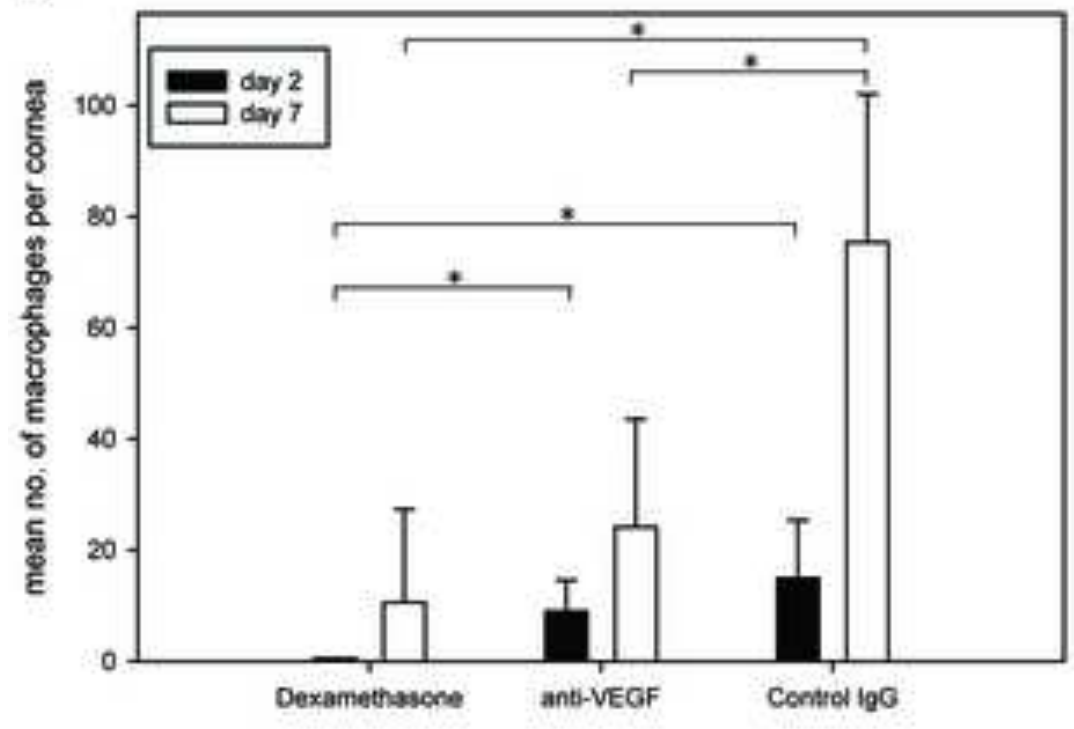

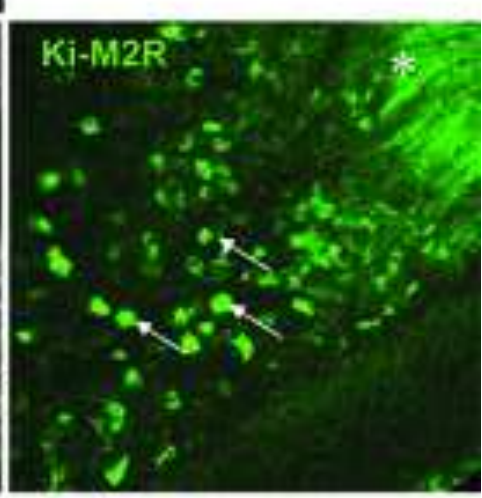




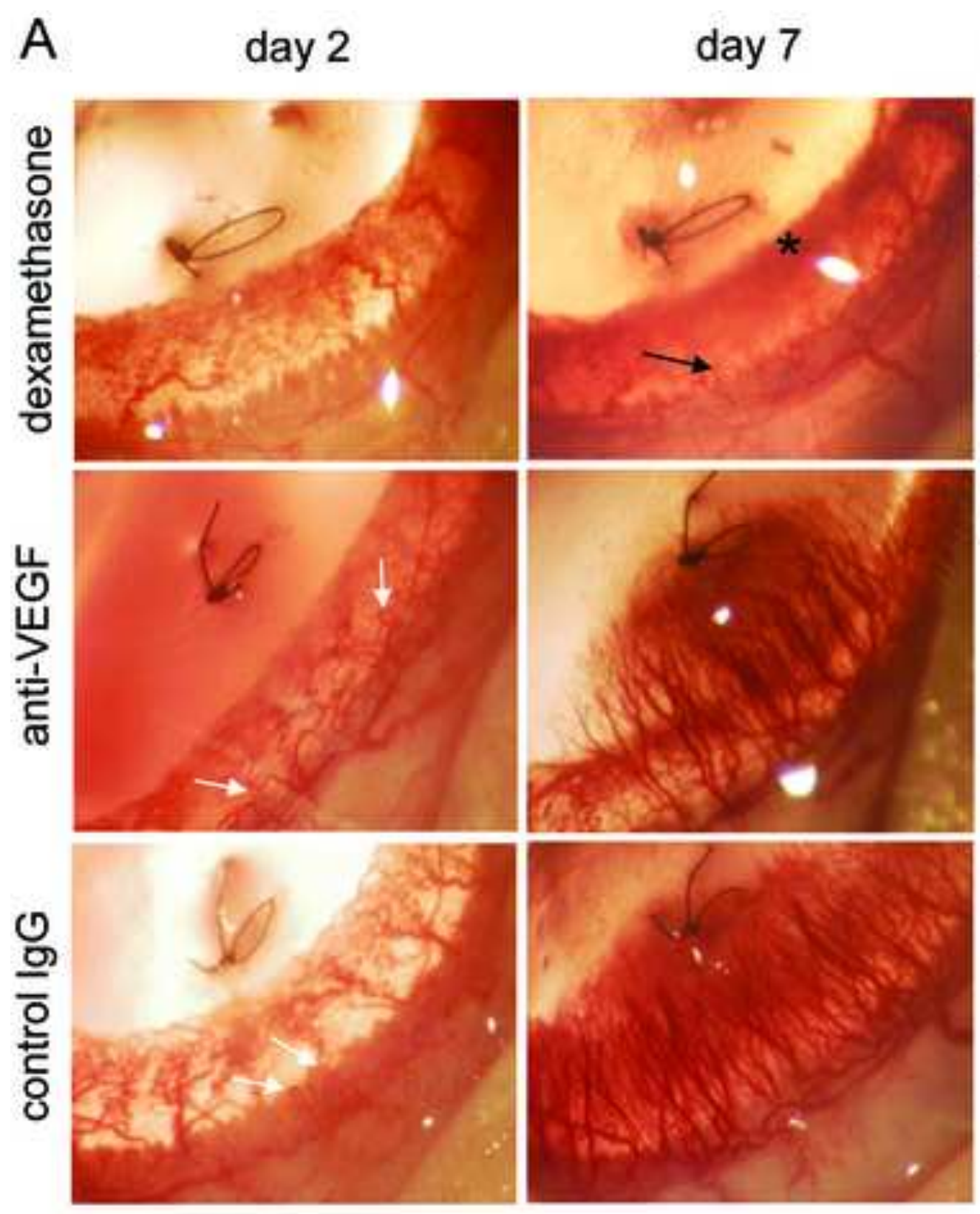

B
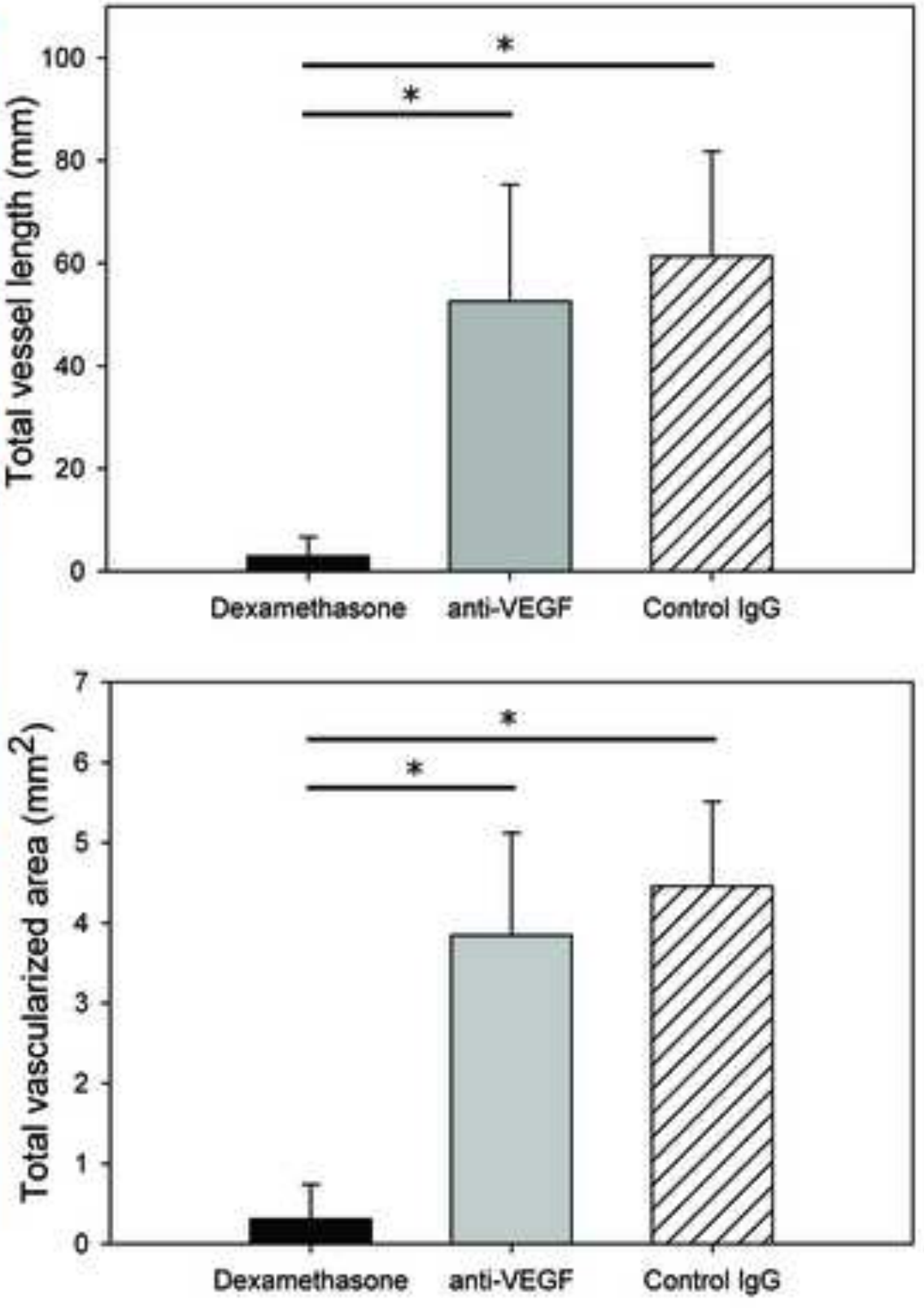

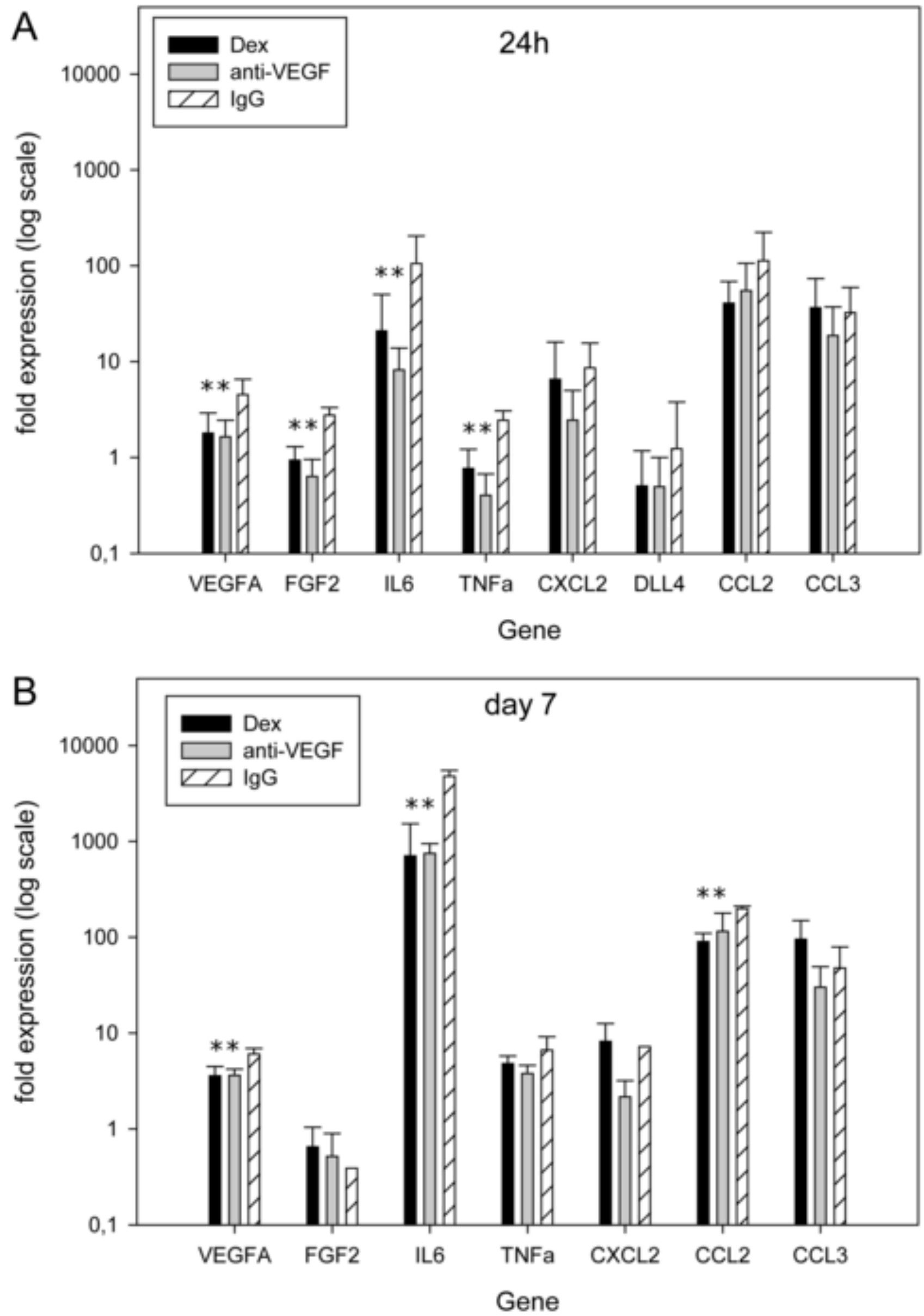